Check for updates

Cite this: RSC Adv., 2017, 7, 31281

\title{
Incorporating doped carbon nanodots and metal ions as an excellent artificial peroxidase for $\mathrm{H}_{2} \mathrm{O}_{2}$ detection $\uparrow$
}

\author{
Feng Li, Xian-He Yu, Fen-Ying Kong, Zhong-Xia Wang (D) and Wei Wang* \\ Novel nitrogen-doped carbon nanodots (NCdots) were successfully synthesized by a hydrothermal method \\ using 1-(3-dimethylaminopropyl)-3-ethylcarbodiimide hydrochloride (EDC) as a carbon-nitrogen source. \\ The NCdots were characterized by methods including TEM, EDX, SAED, XPS, and UV-vis. The NCdots \\ were found to possess intrinsic chromogenic activity, which could be used as an excellent artificial \\ peroxidase to oxidize $\mathrm{H}_{2} \mathrm{O}_{2}$ catalytically by metal ions to produce a chromogenic reaction. The reason \\ for the chromogenic mechanism might be attributed to the structural alteration of NCdots by free \\ radical scavenging similar to Fenton's reagent in the presence of $\mathrm{H}_{2} \mathrm{O}_{2}$. This offers a simple and selective \\ colorimetric method for the determination of some metal ions in environmental systems.
}

Received 7th May 2017

Accepted 7th June 2017

DOI: $10.1039 / \mathrm{c} 7 \mathrm{ra05146h}$

rsc.li/rsc-advances

of doped Cdots in metal ion and biomolecule detection based

\section{Introduction}

Carbon-based nanodots consisting of graphene quantum dots (GQDs) and carbon quantum nanodots (CQDs, Cdots or CDs) are a new species of carbon nanomaterial with sizes less than $10 \mathrm{~nm} .{ }^{1}$ As a consequence of their special surface state and unique physical and chemical properties, carbon-based nanodots have gradually become an important new nanocarbon member due to their benign, abundant and inexpensive nature. ${ }^{2,3}$ Nevertheless, to date, nearly all applications of pure carbon-based nanodots have low surface activity limiting their application. ${ }^{4,5}$ Compared with pure carbon nanodots (Cdots), doping Cdots with heteroatoms is more attractive for analytical applications due to their outstanding intrinsic properties including higher photostability and fluorescent quantum yield, low photobleaching, more surface-passivated groups, and other special physicochemical properties. ${ }^{6-8}$ Moreover, doped Cdots are commonly biocompatible and have low toxicity, which makes them superior to quantum dots. ${ }^{2}$ Recently, applications

School of Chemistry and Chemical Engineering, Yancheng Institute of Technology, Yancheng 224051, P. R. China. E-mail:wangzx198411@163.com; wangw@ycit.edu.cn $\dagger$ Electronic supplementary information (ESI) available. See DOI: $10.1039 / \mathrm{c} 7 \mathrm{ra05146h}$

Feng Li received his M.S. degree from Changzhou University, China in 2008. His current fields of interest are electrochemical catalysis and bio-analytical chemistry. on their optical characteristics have been demonstrated by several groups. ${ }^{9-12}$ These applications are important and attractive. Up to now, the surface activity of the doped Cdots as an artificial peroxidase has rarely been reported although there are some studies on intrinsic enzymatic activities of Cdots. ${ }^{13}$ Herein, we demonstrate the intrinsic chromogenic activity of doped Cdots in the oxidation of $\mathrm{H}_{2} \mathrm{O}_{2}$ catalytically in the presence of some metal ions to produce a brown color.

Hydrogen peroxide $\left(\mathrm{H}_{2} \mathrm{O}_{2}\right)$, as a principal member of the reactive oxygen class and a by-product of reactions catalyzed by many oxidase enzymes, plays important roles in biological systems, and industrial, pharmaceutical, and other fields. ${ }^{\mathbf{1 4}}$ Therefore, the development of effective analytical methods for the selective detection of trace amounts of $\mathrm{H}_{2} \mathrm{O}_{2}$ is an especially important subject in current chemical research. To date, various traditional techniques and methods, including electrochemical strategies, spectroscopic approaches, and enzymatic methods, have been developed for $\mathrm{H}_{2} \mathrm{O}_{2}$ detection. ${ }^{15-17}$ Among them, enzymatic methods of detection have proved to be very powerful owing to their high substrate specificity and efficiency. However, limited natural sources, high-cost purification processes, time-consuming preparation, easy inactivation and inherent instability restrict their applications to some extent. To
Xian-He Yu received his B.S. degree in Applied Chemistry from Nanjing Teach University, China in 2014. He is now a joint training Master of Organic Chemistry in the School of Chemistry and Chemical Engineering, Yancheng Institute of Technology. His research interests are in the areas of fluorescence probe and electrochemical analysis. 
overcome these drawbacks, increasing attention has focused on enzyme mimetics. Compared with natural enzymes, the efficiency of most non-enzymes is still lower, especially enzyme activity, and which can be dramatically decreased by the addition of coatings and bioconjugation. Thus, developing a convenient and simple method for the preparation of nanomaterials with intrinsic enzymatic activities remains highly desirable before using enzymatic techniques for $\mathrm{H}_{2} \mathrm{O}_{2}$ detection.

In this work, a one-pot simple green method was developed to synthesize nitrogen-doped Cdots (NCdots) using 1-(3dimethylaminopropyl)-3-ethylcarbodiimide hydrochloride (EDC) as a carbon-nitrogen precursor, without any other additives or further chemical modifications. According to EDX and XPS analysis, the compositions of NCdots were determined, and the results showed that the resultant NCdots possess intrinsic organic redox dye (ORD)-like chromogenic activity, and could oxidize $\mathrm{H}_{2} \mathrm{O}_{2}$ catalytically in the presence of some metal ions to produce a chromogenic reaction. The NCdots were successfully used for the analysis of some metal ions and $\mathrm{H}_{2} \mathrm{O}_{2}$ based on the NCdots and the metal ion reaction.

\section{Experimental}

\section{Reagents and chemicals}

1-(3-Dimethylaminopropyl)-3-ethylcarbodiimide hydrochloride (EDC) was purchased from Sigma-Aldrich. Hydrogen peroxide $\left(\mathrm{H}_{2} \mathrm{O}_{2}\right)$, copper sulfate pentahydrate $\left(\mathrm{CuSO}_{4} \cdot 5 \mathrm{H}_{2} \mathrm{O}\right)$, cobalt chloride hexahydrate $\left(\mathrm{CoCl}_{2} \cdot 6 \mathrm{H}_{2} \mathrm{O}\right)$, manganese chloride tetrahydrate $\left(\mathrm{MnCl}_{2} \cdot 4 \mathrm{H}_{2} \mathrm{O}\right)$, iron sulfate heptahydrate $\left(\mathrm{FeSO}_{4} \cdot 7 \mathrm{H}_{2}\right.$ $\mathrm{O})$, iron chloride $\left(\mathrm{FeCl}_{3}\right)$, chromium chloride hexahydrate $\left(\mathrm{CrCl}_{3} \cdot 6 \mathrm{H}_{2} \mathrm{O}\right)$ and tris(hydroxymethyl)aminoethane (Tris) were obtained from Shanghai Sinopharm Chemical Reagent Co. Ltd. (Shanghai, China). Other chemicals and solvents were of analytical grade and were used without further purification. Double distilled water was used throughout.

\section{Apparatus}

Fluorescence (FL) spectra were recorded on a Fluoromax-4 fluorescence spectrofluorometer (Horiba, USA). UV-vis absorption spectra were recorded on a Shimadzu UV-2550 spectrophotometer (Tokyo, Japan). Transmission electron microscopy

Fen-Ying Kong is a lecturer in Yancheng Institute of Technology, China. She received her Ph.D. degree in analytical chemistry from Nanjing University in 2012. Her research is focused on the preparation of new functional nanomaterials and electrochemical sensing applications.

Zhong-Xia Wang obtained her Ph.D. degree in 2016 from Southeast University, China. She is a Lecturer in the School of Chemistry and Chemical Engineering, Yancheng Institute of Technology. Her current fields of interest are photoluminescent carbon-based nanomaterials and bio-analytical chemistry.
(TEM) and selected-area electron diffraction (SAED) patterns were conducted on a JEM-2100 transmission electron microscope (JEOL Ltd.). Energy dispersive X-ray spectroscopy (EDX) was carried out using a FEI Sirion 200 scanning electron microscope (FEI). X-ray photoelectron spectroscopy (XPS) analysis was performed on a Thermo ESCALAB 250XI X-ray photoelectron spectrometer (USA).

\section{Synthesis of NCdots}

Fluorescent NCdots were prepared by traditional hydrothermal treatment of EDC. Briefly, $0.55 \mathrm{~g}$ of EDC was dissolved in 12.5 $\mathrm{mL}$ of deionized water and $12.5 \mathrm{~mL}$ of ethanol to form a homogeneous solution under sonication. The $25 \mathrm{~mL}$ asprepared solution was then put into a poly(tetrafluoroethylene) (Teflon)-lined autoclave and heated at $180^{\circ} \mathrm{C}$ for $8.0 \mathrm{~h}$, and then cooled to room temperature naturally. The resulting solution was centrifuged at $10000 \mathrm{rpm}$ for $30 \mathrm{~min}$ to remove the solid residue, and a brown-yellow aqueous solution of NCdots was obtained.

\section{Fluorescent detection procedure for $\mathrm{H}_{2} \mathrm{O}_{2}$}

For the $\mathrm{H}_{2} \mathrm{O}_{2}$ sensing experiments, solutions of $50 \mu \mathrm{L}$ Tris$\mathrm{HNO}_{3}$ buffer (50 mM, pH 6.0), $10 \mu \mathrm{L}$ NCdots $\left(1 \mathrm{mg} \mathrm{mL}{ }^{-1}\right), 50 \mu \mathrm{L}$ $\mathrm{Cu}^{2+}$ ion $(1.0 \mathrm{mM})$, and different amounts of $\mathrm{H}_{2} \mathrm{O}_{2}$ solution were added to a centrifuge tube $(1.5 \mathrm{~mL})$. Then, the solution was completely mixed with a vortex mixer at room temperature for a few seconds to accelerate the reaction. The final volume of the mixture was adjusted to $500 \mu \mathrm{L}$ with double distilled water. The mixture was equilibrated at room temperature for $30 \mathrm{~min}$ before FL spectra measurements were recorded. The resulting solutions were studied by FL spectra at room temperature with excitation at $330 \mathrm{~nm}$, and both the excitation and emission slit widths were $5 \mathrm{~nm}$.

\section{Results and discussion}

\section{Synthesis and characterization of fluorescent NCdots}

TEM was performed to observe the morphology of the prepared NCdots. A TEM image of the NCdots supported on carbon nanodots synthesized using EDC as the carbon-nitrogen source in the precursor solution is shown in Fig. 1A. The NCdots thus formed are uniform, monodisperse, and the corresponding particle size distribution histogram (inset in Fig. 1A) indicates that these carbon nanodots have diameters ranging from 5.0 to $7.0 \mathrm{~nm}$ (50 NCdots have been used to calculate the size distribution, RSD 5.17\%). The HRTEM image in the inset of Fig. 1A clearly reveals that the diffraction contrast of the NCdots is very high and with obvious lattice fringes $(2.17 \AA)$, which is consistent with the (102) diffraction planes of $\mathrm{sp}^{2}$ graphitic carbon,

Wei Wang received his B.S. and Ph.D. degrees in analytical chemistry from Nanjing University, China in 1991 and 2007, respectively. He is now a professor at Yancheng Institute of Technology, China. His research interests are in the areas of microfluidics and electrochemical detection. 

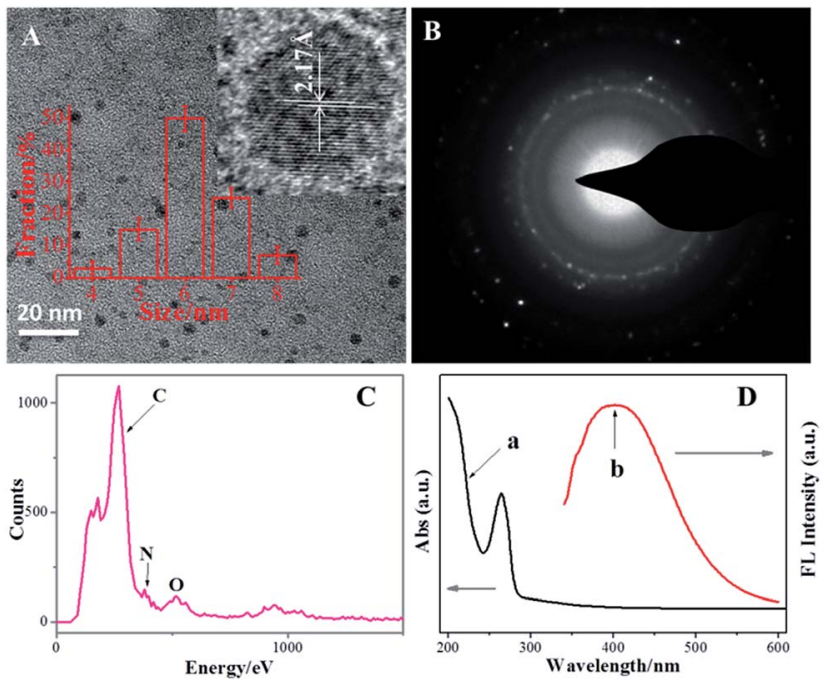

Fig. 1 TEM image (A), SAED image (B), EDX (C), and UV-vis/FL spectra (D) of the NCdots. Inset in (A) shows the diameter distribution and HRTEM of the NCdots.

implying that the NCdots maintained similar crystallinity to graphene. ${ }^{18}$ So the prepared NCdots are uniform and of high crystallinity. Meanwhile, Fig. 1B shows the SAED pattern of the NCdots. SAED reveals the crystalline nature of the NCdots, as also confirmed in the inset in Fig. 1A. The formation of NCdots was confirmed by EDX as shown in Fig. 1C. EDX measurement of the NCdots revealed the presence of mainly carbon, nitrogen, and oxygen, confirming that nitrogen had been successfully doped in the NCdots (9.069 at\%) by the present one-pot in situ approach.

XPS is often used to determine the surface composition and elemental analysis of carbon nanomaterials. The XPS survey spectrum (Fig. 2A) of the NCdots shows three typical peaks at $285.7,399.8$, and $531.5 \mathrm{eV}$, which are attributed to $\mathrm{C}_{1 \mathrm{~s}}, \mathrm{~N}_{1 \mathrm{~s}}$, and $\mathrm{O}_{1 \mathrm{~s}}$, respectively. The XPS spectrum results indicate that these NCdots are mainly composed of C (83.162\%), as well as a limited
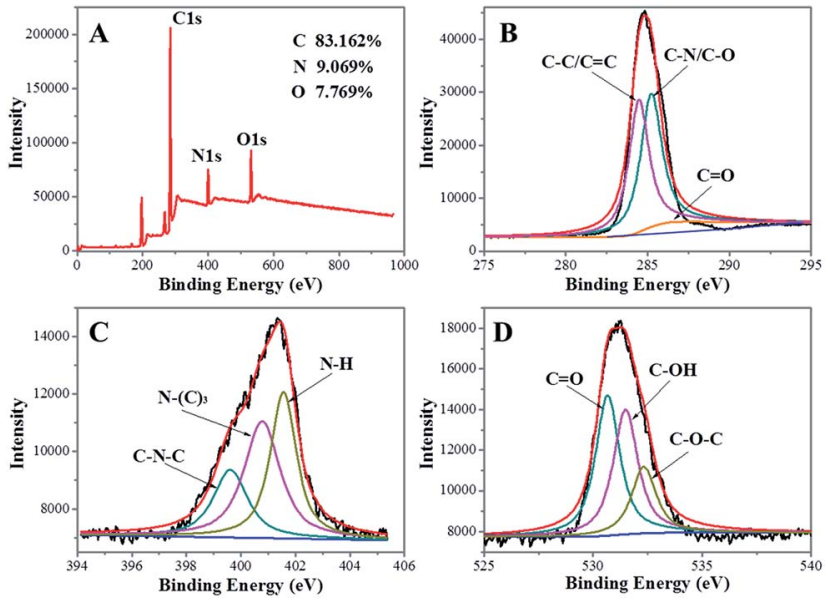

Fig. 2 (A) XPS survey spectra of the as-produced NCdots. Highresolution spectra of $\mathrm{C}_{1 \mathrm{~s}}(\mathrm{~B}), \mathrm{N}_{1 \mathrm{~s}}(\mathrm{C})$ and $\mathrm{O}_{1 \mathrm{~s}}(\mathrm{D})$ in NCdots. amount of $\mathrm{N}(9.069 \%)$ and $\mathrm{O}(7.769 \%)$ elements (the atomic ratio of $\mathrm{C} / \mathrm{N} / \mathrm{O}$ is about $11: 1: 1)$. The high resolution spectrum of $\mathrm{C}_{1 \mathrm{~s}}$ exhibits three main peaks (Fig. 2B). The binding energy peak at $284.5 \mathrm{eV}$ confirms the graphitic structure $\left(\mathrm{sp}^{2}, \mathrm{C}=\mathrm{C}\right)$ of the NCdots. The peaks at about 285.3 and $286.5 \mathrm{eV}$ suggest the presence of $\mathrm{C}-\mathrm{N} / \mathrm{C}-\mathrm{O}$ and $\mathrm{C}=\mathrm{O}$ groups, respectively. ${ }^{3}$ The highresolution spectrum of $\mathrm{N}_{1 \mathrm{~s}}$ (Fig. 2C) shows three peaks at 399.6, 400.7 and $401.5 \mathrm{eV}$, which are attributed to the $\mathrm{C}-\mathrm{N}-\mathrm{C}, \mathrm{N}-(\mathrm{C})_{3}$, and $\mathrm{N}-\mathrm{H}$ bands, respectively. ${ }^{19}$ The $\mathrm{O}_{1 \mathrm{~s}}$ spectrum (Fig. 2D) shows three peaks at 530.6, 531.5, and $532.4 \mathrm{eV}$, which are attributed to $\mathrm{C}=\mathrm{O}, \mathrm{C}-\mathrm{OH}$ and $\mathrm{C}-\mathrm{O}-\mathrm{C}$ groups, respectively. ${ }^{6}$ Such observations also suggest that the NCdots have a graphitic carbon structure. Therefore, we could conclude that the NCdots obtained are mainly composed of polycyclic heterocyclic aromatic $\mathrm{C}=\mathrm{C}$ species derived from the dehydration and polymerization of EDC and ethanol, as well as possessing abundant hydroxyl, amino and carbonyl moieties on their surface.

Fig. 1D shows that the suspension of NCdots has a typical UVvis absorption peak at $263 \mathrm{~nm}$ with a weak shoulder at $\sim 330 \mathrm{~nm}$. The absorption peak at $\sim 263 \mathrm{~nm}$ was assigned to the $\sigma-\pi$ and $\pi-$ $\pi^{*}$ transitions originating from the carbene-like triplet state of aromatic $\mathrm{sp}^{2}$ domains of carbon nanodots, which leads to virtually no observed FL signal, ${ }^{20}$ while the other transition centered at $\sim 330 \mathrm{~nm}$ is due to the trapping of excited-state energy by the surface states and results in strong emission. ${ }^{21}$ An excitationdependent emission was observed with the red-shifted emission peaks from long excitation (Fig. S1, ESI†े), showing the multicolor
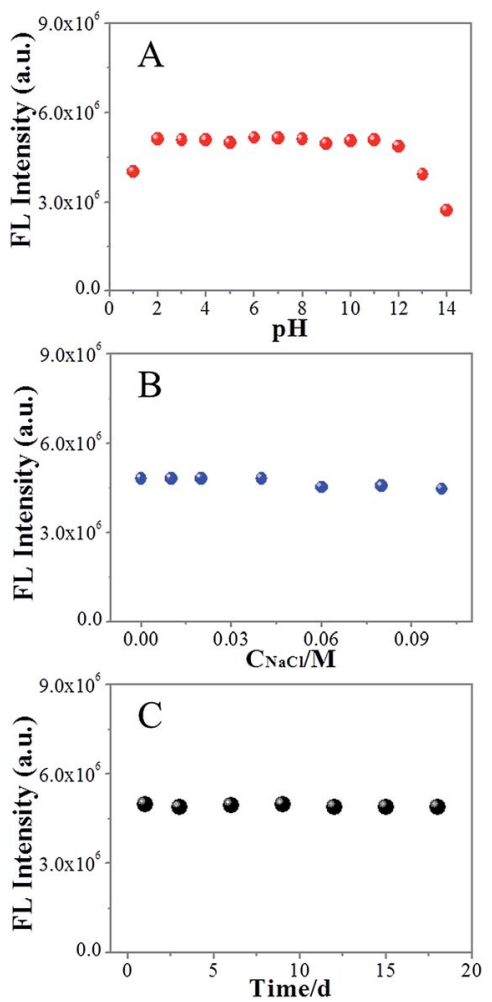

Fig. 3 FL intensity at $390 \mathrm{~nm}$ (excitation at $330 \mathrm{~nm}$ ) of the NCdots at different $\mathrm{pH}$ values (A), different concentrations of $\mathrm{NaCl}$ solution (B), and the stability of the NCdots as a function of storage time (C). RSD ( $n$ $=5$ ) is $4.23 \%(A), 4.57 \%(B)$ and $3.95 \%(C)$, respectively. 
properties of the NCdots and characteristics of carbon materials. ${ }^{22}$ The emission intensity increased in the excitation range of 270$330 \mathrm{~nm}$ and then decreased gradually. The maximum emission peak was observed at $390 \mathrm{~nm}$ for an excitation of $330 \mathrm{~nm}$ (Fig. 1D, curve b).

To study the photostability of NCdots under different conditions, the FL intensity of NCdots was investigated at different $\mathrm{pH}$ values, ionic strength environments and storage times (Fig. 3). Fig. 3A shows the fluorescence intensities of NCdots at different $\mathrm{pH}$ values. It is seen that the FL of the NCdots is strong and stable over a wide range of $\mathrm{pH}$ values (2-12, Fig. 3A). When the $\mathrm{pH}$ value is lower than 2 or higher than 12, the FL intensities decrease gradually. Therefore, the effect of $\mathrm{pH}$ can be understood in terms of the change in surface charge owing to intermolecular and intramolecular protonation/deprotonation, which could be attributed to the presence of $\mathrm{CN}$ units and O-containing groups on the surface and edge. ${ }^{6}$ To confirm the FL stability of NCdots under high ionic strength environments, we measured the FL intensities in the presence of different concentrations of $\mathrm{NaCl}$ (up to $0.1 \mathrm{M}$ ). As shown in Fig. 3B, only a slight change in FL intensity was observed, indicating the high stability of the NCdots even under an environment of high ionic strength. Meanwhile, it is worth mentioning that these NCdots in suspension can be very stable for 18 days, without observation of any floating or precipitated nanodots (Fig. 3C). These results indicate the excellent photostability of the NCdots, probably due to the electrostatic repulsions between the negatively charged nanodots resulting in electrosteric stabilization. These findings indicate that NCdots have great potential for sensing applications under physiological conditions.

\section{Investigation of the chromogenic mechanism}

The organic redox dye (ORD)-like activity of the NCdots was evaluated in the catalysis of $\mathrm{H}_{2} \mathrm{O}_{2}$ in the presence of metal ions.
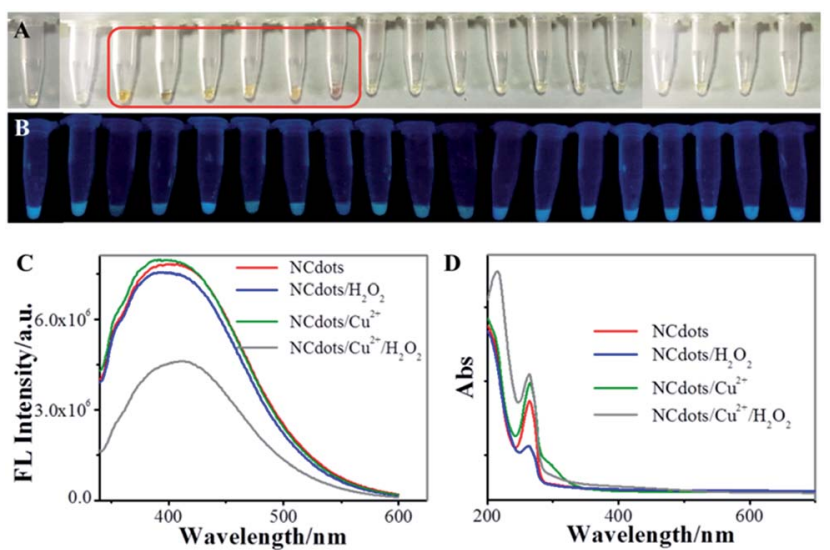

Fig. 4 (A) Images of production of colored products for blank, $\mathrm{H}_{2} \mathrm{O}_{2}$, and $\mathrm{Cu}^{2+}, \mathrm{Mn}^{2+}, \mathrm{Co}^{2+}, \mathrm{Fe}^{2+}, \mathrm{Fe}^{3+}, \mathrm{Cr}^{3+}, \mathrm{Hg}^{2+}, \mathrm{Mg}^{2+}, \mathrm{Ba}^{2+}, \mathrm{K}^{+}, \mathrm{Zn}^{2+}$, $\mathrm{Cd}^{2+}, \mathrm{Sn}^{2+}, \mathrm{Ni}^{2+}, \mathrm{Pb}^{2+}, \mathrm{Ag}^{+}$or $\mathrm{Na}^{+}$in the presence of $\mathrm{H}_{2} \mathrm{O}_{2}$, respectively. (B) Photographs under UV light (365 nm) corresponding to (A). (C) FL spectra of free NCdots and in the presence of $\mathrm{H}_{2} \mathrm{O}_{2}, \mathrm{Cu}^{2+}$ ion, and both $\mathrm{H}_{2} \mathrm{O}_{2}$ and $\mathrm{Cu}^{2+}$ ions, respectively. (D) UV-vis spectra of free NCdots and in the presence of $\mathrm{H}_{2} \mathrm{O}_{2}, \mathrm{Cu}^{2+}$ ion, and both $\mathrm{H}_{2} \mathrm{O}_{2}$ and $\mathrm{Cu}^{2+}$ ions, respectively.
NCdots could catalyze $\mathrm{H}_{2} \mathrm{O}_{2}$ in the presence of some metal ions, and produced a typical chromogenic reaction. As shown in Fig. 4A, six stronger chromogenic reactions were observed for NCdots upon addition of $\mathrm{Cu}^{2+}, \mathrm{Mn}^{2+}, \mathrm{Co}^{2+}, \mathrm{Fe}^{2+}, \mathrm{Fe}^{3+}$ or $\mathrm{Cr}^{3+}$ ions, while other metal ions were not able to exert a significant chromogenic reaction. Based on the above results, it can be speculated that the chromogenic mechanism might be attributed to the structural alteration of NCdots by the excellent $\mathrm{OH}^{*}$ radical scavenging properties in the presence of $\mathrm{H}_{2} \mathrm{O}_{2}$, like Fenton's reagent, resulting in the mixed solution showing a chromogenic reaction. ${ }^{23,24}$ It is well-known that $\mathrm{OH}^{-}$radicals can be generated, as with Fenton's reagent, in which these six metal ions react with $\mathrm{H}_{2} \mathrm{O}_{2}$, producing $\mathrm{OH}^{\cdot}$ radicals and metal hydroxides (eqn (1)). ${ }^{25}$ Meanwhile, the FL intensity of these mixed solutions can be easily observed visually under UV light (365 nm), and the solution of NCdots in the presence of $\mathrm{Cu}^{2+}$ ions exhibits weak FL intensity (Fig. 4B). In contrast, the FL intensity of NCdots shows no obvious change in the presence of the other metal ions which perhaps produce the chromogenic reaction, simultaneously, accompanied by specific chelation between $\mathrm{Cu}^{2+}$ ion and NCdots resulting in $\mathrm{FL}$ quenching. Inspired by the fact that the fluorescence intensity of NCdots depends on the presence of $\mathrm{H}_{2} \mathrm{O}_{2}$, a straightforward strategy for $\mathrm{H}_{2} \mathrm{O}_{2}$ sensing has been explored based on NCdots and $\mathrm{Cu}^{2+}$ ion (Fig. 4C and D).

$$
\mathrm{M}^{2+}+\mathrm{H}_{2} \mathrm{O}_{2} \rightarrow \mathrm{MOH}^{2+}+\mathrm{OH}^{\cdot}
$$

\section{Condition optimization}

In order to obtain optimal $\mathrm{H}_{2} \mathrm{O}_{2}$ sensing, the $\mathrm{Cu}^{2+}$ ion concentration was investigated. Fig. 5 shows the alteration of fluorescence of NCdots at various concentrations of $\mathrm{Cu}^{2+}$ ions. The relative $\mathrm{FL}$ intensity $\left(\mathrm{FL}_{0} / \mathrm{FL}\right)$ at $390 \mathrm{~nm}$ increases in the concentration range of $0.01-0.1 \mathrm{mM}$ and then decreases

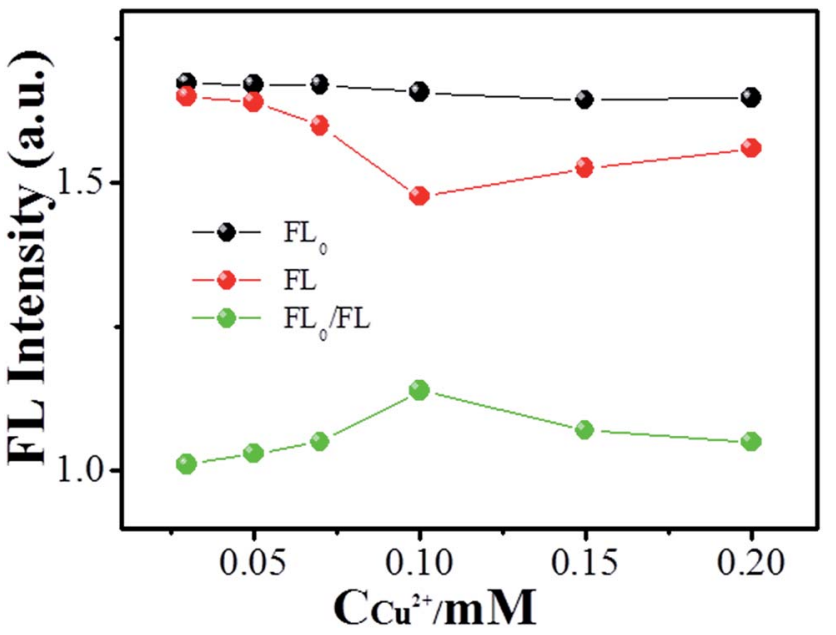

Fig. 5 Influence of $\mathrm{Cu}^{2+}$ ions on $\mathrm{FL}$ quenching in the concentration range $0.01-0.2 \mathrm{mM} \mathrm{Cu}^{2+}$. The black profile is for $\mathrm{NCdots}$ alone, the red profile is for $\mathrm{NCdots} / \mathrm{Cu}^{2+}$ in the presence of $\mathrm{H}_{2} \mathrm{O}_{2}$, and the green profile shows the ratio of $\mathrm{NCdots}$ alone to $\mathrm{NCdots} / \mathrm{Cu}^{2+}$. Concentration: NCdots: $20 \mu \mathrm{g} \mathrm{mL}^{-1}, \mathrm{H}_{2} \mathrm{O}_{2}: 500 \mathrm{mM}$, Tris- $\mathrm{HNO}_{3}$ buffer, $\mathrm{pH}$ 6.0. 
gradually. The reason for this phenomenon may be because there is chelation between $\mathrm{OH}^{*}$ radicals and $\mathrm{Cu}^{2+}$ ions at high concentrations of metal ions and, therefore, the resulting reduced chemical reaction between NCdots and $\mathrm{OH}^{*}$ radicals will make them soluble in aqueous media with high concentrations of metal ions. That is, $\mathrm{Cu}^{2+}$ ions could complex with $\mathrm{OH}^{\cdot}$ radicals to form the insoluble hydrated oxide $\mathrm{Cu}(\mathrm{OH})_{2}$ under high concentration conditions, preventing coordination of $\mathrm{OH}^{*}$ radicals with the NCdots, leading to incomplete FL quenching due to suppression of the alteration of the molecular structure of NCdots. With respect to this sensitivity, a concentration of $0.1 \mathrm{mM}$ of $\mathrm{Cu}^{2+}$ ions was selected as an intermediate mediator for $\mathrm{H}_{2} \mathrm{O}_{2}$ detection.

\section{Sensitive and selective sensing of $\mathrm{H}_{2} \mathrm{O}_{2}$}

On the basis of the above discussion, we explored the feasibility of using NCdots as a FL probe for the detection of $\mathrm{H}_{2} \mathrm{O}_{2}$ under optimal conditions (Tris- $\mathrm{HNO}_{3}$ buffer of $\mathrm{pH} 6.0, \mathrm{Cu}^{2+}$ ion: 0.1 $\mathrm{mM}$ ), as shown in Fig. 6. Fig. 6A shows the FL responses of NCdots $/ \mathrm{Cu}^{2+}$ complexes when different concentrations of $\mathrm{H}_{2} \mathrm{O}_{2}$ were added into the system, and sequential decreases of the FL emission at $390 \mathrm{~nm}$ were observed with increasing concentrations of $\mathrm{H}_{2} \mathrm{O}_{2}$. The $\mathrm{H}_{2} \mathrm{O}_{2}$ dependence plot (Fig. $6 \mathrm{~B}$ ) of $\left[\left(\mathrm{FL}_{0}-\right.\right.$ $\left.\mathrm{FL}) / \mathrm{FL}_{0}\right]\left(\mathrm{FL}_{0}\right.$ and $\mathrm{FL}$ are the highest fluorescence intensities of NCdots $/ \mathrm{Cu}^{2+}$ complexes excited at $330 \mathrm{~nm}$ in the absence and presence of $\mathrm{H}_{2} \mathrm{O}_{2}$, respectively) showed good linearity with $\mathrm{H}_{2} \mathrm{O}_{2}$ concentration in the range $0.05-300 \mathrm{mM}$. The limit of detection (LOD) for $\mathrm{H}_{2} \mathrm{O}_{2}$, at a signal-to-noise ratio of three, was estimated to be $15.89 \mu \mathrm{M}(3 \delta)$. Such a high LOD might be attributed to indirect detection rather than direct detection through FL of NCdots.

Considering the promise of the NCdots $/ \mathrm{Cu}^{2+}$ complex sensor system for application in the biological and environmental fields, the selectivity of the FL sensor for $\mathrm{H}_{2} \mathrm{O}_{2}$ was evaluated. Under optimal conditions, we repeated the FL intensity changes of the NCdots $/ \mathrm{Cu}^{2+}$ complexes in the presence of competitive biomolecules five times under the same conditions, respectively, including uric acid (UA), dopamine (DA), ascorbic acid (AA), and glucose (Glu), as shown in Fig. S2 $\uparrow$ (RSD, 3.85\%, $n=$ 5). A higher FL quenching was observed for NCdots upon addition of $\mathrm{H}_{2} \mathrm{O}_{2}$ in the presence of $\mathrm{Cu}^{2+}$ ions $(0.1 \mathrm{mM})$, while
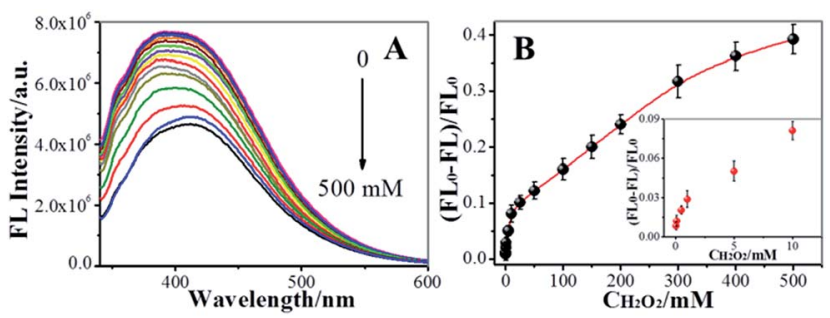

Fig. 6 (A) FL emission spectra of $\mathrm{NCdots} / \mathrm{Cu}^{2+}$ in the presence of different concentrations of $\mathrm{H}_{2} \mathrm{O}_{2}(0,0.05,0.1,0.5,1.0,5.0,10.0,25.0$, 50.0, 100.0, 150.0, 200.0, 300.0, 400.0, $500.0 \mathrm{mM}$, top to bottom, excitation at $330 \mathrm{~nm})$. (B) Plot of the enhanced FL signals [(FL $-\mathrm{FL})$ / $\mathrm{FL}_{0}$ ] versus $\mathrm{H}_{2} \mathrm{O}_{2}$ concentration. Concentration: NCdots: $20 \mu \mathrm{g} \mathrm{mL}^{-1}$, $\mathrm{Cu}^{2+}$ : $0.1 \mathrm{mM}$, Tris $-\mathrm{HNO}_{3}$ buffer, $\mathrm{pH}$ 6.0. the other substances were not able to exert a significant quenching effect. Therefore, these observations suggest that the proposed method is capable of discriminating between $\mathrm{H}_{2} \mathrm{O}_{2}$ and the interfering biomolecules.

\section{Conclusions}

In this study, we have successfully synthesized one type of NCdots through a simple, one-pot, hydrothermal approach, in which EDC was used as the carbon-nitrogen source. We also found that, in the chromogenic reaction, six metal ions play an important role in determining the chromogenic reagent properties of the prepared NCdots. Based on the results, for the first time, NCdots were successfully applied as an artificial peroxidase to detect multi-metal ions and $\mathrm{H}_{2} \mathrm{O}_{2}$. The green synthesis method of NCdots using EDC was feasible and could have economic benefits.

\section{Acknowledgements}

We greatly appreciate the support of the National Natural Science Foundation of China (21575123, 21675139), and sponsorship from the Qing Lan Project. This is the opening project of Jiangsu Key Laboratory of Biochemistry and Biotechnology of Marine Wetland (K2016-17, K2016-20).

\section{Notes and references}

1 Y. Wang and A. Hu, J. Mater. Chem. C, 2014, 2, 6921-6939.

2 S. N. Baker and G. A. Baker, Angew. Chem., Int. Ed., 2010, 49, 6726-6744.

3 Z. X. Wang, F. Y. Kong and W. Wang, Chem.-Eur. J., 2017, 23, 665-675.

4 L. Zhou, Y. Lin, Z. Huang, J. Ren and X. Qu, Chem. Commun., 2012, 48, 1147-1149.

5 Y. Song, S. Zhu and B. Yang, RSC Adv., 2014, 4, 27184-27200.

6 Z. X. Wang and S. N. Ding, Anal. Chem., 2014, 86, 7436-7445.

7 S. Lu, R. Cong, S. Zhu, X. Zhao, J. Liu, J. S. Tse, S. Meng and B. Yang, ACS Appl. Mater. Interfaces, 2016, 8, 4062-4068.

8 L. Cao, M. J. Meziani, S. Sahu and Y. P. Sun, Acc. Chem. Res., 2013, 46, 171-180.

9 A. Gupta, A. Chaudhary, P. Mehta, C. Dwivedi, S. Khan, N. C. Verma and C. K. Nandi, Chem. Commun., 2015, 51, 10750-10753.

10 Y. Dong, R. Wang, G. Li, C. Chen, Y. Chi and G. Chen, Anal. Chem., 2012, 84, 6220-6224.

11 M. Deng, S. Wang, C. Liang, H. Shang and S. Jiang, RSC Adv., 2016, 6, 26936-26940.

12 J. Song, J. Li, Z. Guo, W. Liu, Q. Ma, F. Feng and C. Dong, RSC Adv., 2017, 7, 12827-12834.

13 W. Shi, Q. Wang, Y. Long, Z. Cheng, S. Chen, H. Zheng and Y. Huang, Chem. Commun., 2011, 47, 6695-6697.

14 B. Liu, Z. Sun, P. J. Huang and J. Liu, J. Am. Chem. Soc., 2015, 137, 1290-1295.

15 H. S. Wang, W. J. Bao, S. B. Ren, M. Chen, K. Wang and X. H. Xia, Anal. Chem., 2015, 87, 6828-6833. 
16 H. H. Zeng, W. B. Qiu, L. Zhang, R. P. Liang and J. D. Qiu, Anal. Chem., 2016, 88, 6342-6348.

17 Y. L. Hu, J. H. Yuan, W. Chen, K. Wang and X. H. Xia, Electrochem. Commun., 2005, 7, 1252-1256.

18 H. J. Sun, N. Gao, L. Wu, J. S. Ren, W. Wei and X. G. Qu, Chem.-Eur. J., 2013, 19, 13362-13368.

19 S. Liu, J. Tian, L. Wang, Y. Zhang, X. Qin, Y. Luo, A. M. Asiri, A. O. Al-Youbi and X. Sun, Adv. Mater., 2012, 24, 2037-2041. 20 Y. Li, Y. Hu, Y. Zhao, G. Q. Shi, L. E. Deng, Y. B. Hou and L. T. Qu, Adv. Mater., 2011, 23, 776-780.
21 Y. P. Sun, X. Wang, F. Lu, L. Cao, M. J. Meziani, P. G. Luo, L. Gu and L. M. Veca, J. Phys. Chem. C, 2008, 112, 1829518298.

22 Y. Xu, M. Wu, X. Z. Feng, X. B. Yin, X. W. He and Y. K. Zhang, Chem.-Eur. J., 2013, 19, 6282-6288.

23 W. K. Pogozelski and T. D. Tullius, Chem. Rev., 1998, 98, 1089-1108.

24 A. C. Jacobs, M. J. E. Resendiz and M. M. Greenberg, J. Am. Chem. Soc., 2010, 132, 3668-3669.

25 L. Zhang, R. P. Liang, S. J. Xiao, J. M. Bai, L. L. Zheng, L. Zhan, X. J. Zhao, J. D. Qiu and C. Z. Huang, Talanta, 2014, 118, 339-347. 